\title{
O QUE ESTE TEXTO QUER [OU NÃO QUER] DIZER?
}

\author{
Daiane Lopes ${ }^{1}$ \\ Eunice Piazza Gai
}

\section{RESUMO}

Sabemos que a literatura suscita conhecimento. O processo de aprendizado através da leitura literária perpassa todas as fases da vida. No entanto, uma definição para esse tipo de conhecimento é complexa, já que ele é subjetivo e manifesta-se de modo muito individual. Isso ocorre devido ao diálogo que acontece entre texto, autor e leitor. Se cada indivíduo carrega consigo um texto, ao lermos, a nossa produção de sentidos irá diferir da produção dos demais leitores. Dessa forma, exporemos, no presente estudo, algumas reflexões sobre o conhecimento propiciado pela leitura literária. Primeiramente, apresentaremos uma síntese do conto "Em Casa", de Anton Pavlovitch Tchekhov, texto que motivou a realização do artigo e que servirá de exemplo para todas as ponderações apresentadas. Em seguida, realizaremos algumas considerações sobre a literatura infantil, considerando-a como o início do contato com o texto literário. Argumentaremos sobre os efeitos da literatura tanto em adultos quanto em crianças, assim como sobre as maneiras de apresentação de tal arte ao leitor. Por fim, tentaremos caracterizar o conhecimento provocado por ela, tendo como base, entre outros, autores como Vigotsky e Umberto Eco. O texto é composto de questionamentos e de possíveis respostas, já que não tem a intenção de exibir convicções, mas de promover reflexões sobre a temática. Em nossa investigação teórica, percebemos, então, que não há como replicarmos à indagação sobre "o que um texto quer dizer", questionamento que intitula o artigo. Tal resposta irá sofrer variações todas as vezes que a leitura for feita por leitores diferentes ou até mesmo quando o mesmo leitor ler o mesmo texto outra vez. As possíveis respostas, na realidade, estarão respondendo a uma outra questão: como é o conhecimento propiciado pela literatura? Para este, apresentaremos algumas possibilidades de análise: um conhecimento que é singular, o conhecimento de si, mas ao mesmo tempo o conhecimento do mundo. Nesse sentido, este texto dá 
margens para a construção da reflexão sobre aspectos fundamentais em nossa vida: o desejo de ler e de conhecer, o papel da subjetividade e a presença da incerteza.

Palavras-chave: Leitura. Literatura Infantil. Conhecimento. Narrativa.

\section{¿LO QUE ESTE TEXTO QUIERE [O NO QUIERE] DECIR?}

\section{RESUMEN}

Sabemos que la literatura suscita conocimiento. El proceso de aprendizaje a través de la lectura literaria acompaña todas las fases de la vida. Sin embargo, una definición para ese tipo de conocimiento es compleja, ya que él es subjetivo y se manifiesta de modo muy individual. Eso ocurre debido al diálogo que pasa entre texto, autor y lector. Se cada individuo carga consigo un texto, al leer, nuestra producción de sentidos irá diferir de la producción de los demás lectores. De esa forma, expondremos, en el presente estudio, algunas reflexiones sobre el conocimiento propiciado por la lectura literaria. Primeramente, presentaremos una síntesis del cuento "En Casa", de Anton Pavlovitch Tchekhov, texto que motivó la realización del artículo y que servirá de ejemplo para todas las ponderaciones presentadas. Enseguida, realizaremos algunas consideraciones sobre la literatura infantil, considerándola como el inicio del contacto con el texto literario. Argumentaremos sobre los efectos de la literatura tanto en adultos como en niños, así como sobre las maneras de presentación de tal arte al lector. Finalmente, intentaremos caracterizar el conocimiento provocado por la literatura, teniendo como base, entre otros, autores como Vigotsky y Umberto Eco. El texto es compuesto de cuestionamientos y de posibles respuestas, ya que no posee la intención de exhibir convicciones, pero de promover reflexiones sobre la temática. En nuestra investigación teórica, percibimos, entonces, que no es posible contestar a la indagación sobre "lo que un texto quiere decir", cuestionamiento que intitula el artigo. Tal respuesta irá sufrir variaciones todas las veces que la lectura fuere hecha por lectores diferentes o hasta mismo cuando el mismo lector leer el mismo texto otra vez. Las posibles respuestas, en realidad, estarán respondiendo a una otra cuestión: 
¿cómo es el conocimiento propiciado por la literatura? Para este, presentaremos algunas posibilidades de análisis: un conocimiento que es singular, el conocimiento de si mismo, pero al mismo tiempo el conocimiento del mundo. En este sentido, este texto da márgenes para la construcción de la reflexión sobre aspectos fundamentales en nuestra vida: el deseo de leer y de conocer, el papel de la subjetividad, la presencia de la incerteza.

Palabras clave: Lectura. Literatura Infantil. Conocimiento. Narrativa.

\section{TCHEKHOV ENSINA?}

Iniciamos esta reflexão com um questionamento: que tipo de conhecimento a leitura literária produz? Afinal, já não se faz necessário indagar se a literatura propicia conhecimento, pois sentimos seus efeitos a cada leitura realizada. Restanos, então, questionar sobre como podemos defini-lo, caracterizá-lo. A teoria de que a literatura propicia certo tipo de informação pode ser comprovada pelos inúmeros resultados suscitados durante e após o ato de ler. Citamos, como exemplo, o fato de um texto literário ter impulsionado a produção de outro "dizer" sobre ele, o qual se consolida pela elaboração deste artigo.

Ao lermos o conto "Em casa", de Anton Pavlovitch Tchekhov, renomado novelista e dramaturgo russo, iniciamos um processo de reflexão sobre os efeitos da forma artística. É como se aquilo que, de uma maneira fictícia, acontece no conto também ocorresse conosco enquanto leitores, embora sob perspectivas diferenciadas. Nesse sentido, na tentativa de embasar a teoria a ser apresentada, sintetizaremos o texto que incentivou esta escritura.

No já citado conto, a governanta da casa do senhor Pietróvitch, procurador do tribunal regional, percebe que o pequeno Seriója fuma. Imediatamente, o patrão é comunicado e, na tentativa de persuadir o filho sobre os efeitos negativos provocados pelo cigarro, inicia um diálogo com o menino de apenas sete anos. A criança é, então, exposta a uma série de concepções morais e éticas a partir de três ações inadequadas que comete: fumar, mexer nos pertences alheios (os cigarros se encontravam em meio às coisas do pai) e mentir. Tentativas vãs! Tudo o que o pai Ihe fala parece não Ihe fazer o mínimo de sentido, como se enganchar uma frase na 
outra e imitar o linguajar infantil não gerasse nenhum efeito. Aos poucos, Pietróvitch vai se dando conta de que o menino possui um fluxo de pensamento próprio, que vive em um mundo que é só seu e que, desse jeito, compreende o que se passa ao seu redor. Percebendo que toda a sua argumentação não trouxe o resultado desejado, obriga o filho a dizer que lhe dá palavra de honra, dizendo que não mais fumaria. Imediatamente, entende que o conceito de palavra de honra também não é claro para o menino. Conclui, dessa maneira, que "as crianças como os selvagens têm a sua própria visão artística e exigências singulares, inacessíveis à compreensão do adulto." (TCHEKHOV, 2009, p. 46).

No entanto, através da contação de uma história, hábito que Pietróvitch cultivava todas as noites antes de o filho dormir, Seriója toma conhecimento de tudo aquilo que o pai havia the explicado. O pai, ao improvisar uma narrativa, dá uma forma artística para tudo aquilo que havia falado ao filho. Conta-lhe de um senhor que vivia em um bosque e que tinha um filho que fumava. $O$ filho acabou morrendo de tuberculose e, assim, o senhor ficou sem apoio algum. Tudo aquilo que era lindo em seu castelo foi destruído, pois o homem já não tinha mais com quem contar. Ouvindo tal narrativa, o pequeno Seriója, após a conclusão do texto, olha para o pai e diz: "Não vou fumar mais..." (TCHEKHOV, 2009, p. 49).

Através daquele recurso ficcional, uma história, Pietróvitch consegue "ensinar" ao filho tudo aquilo que não havia conseguido com diálogos moralizantes. Ao iniciar a história, o pai não sabia o efeito que seria gerado. Ele poderia ser positivo ou negativo. Vigotsky (2005) nos diz que, em muitos casos, a utilização do texto literário como suposição acerca de regras morais pode promover um efeito contrário. O pai, por exemplo, poderia ter dito: "essa história quis dizer que..." Mas não foi necessário! A forma artística do texto literário gera um tipo de conhecimento que é inexplicável. A arte fez com que o menino aprendesse algo sobre aquele episódio da vida e modificasse uma atitude, um modo de comportamento.

Da mesma forma com que a história contada pelo pai gerou determinado efeito no menino, o texto escrito por Tchekhov nos propiciou determinado conhecimento e fez com que, em nós, manifestasse-se o desejo de investigar as experiências vivenciadas pelas personagens na obra de ficção também no plano real, ou seja, as consequências do ato de ler. Nessa perspectiva, o presente texto reflete sobre os efeitos gerados pela literatura sob o viés da subjetividade do humano, isto é, como ela é capaz de ensinar mesmo sem ter o objetivo. Iremos propor um apanhado de 
fatores na tentativa de caracterizar o conhecimento propiciado pela leitura literária, levando em consideração a fase de iniciação do estímulo ao processo de ler e de sentir o texto: o contato com a literatura infantil.

\section{COMO O CONHECIMENTO SE INICIA?}

Falar de literatura exige a imersão em um mundo de fantasias, em que a realidade se mescla com o fictício. Então, discorreremos sobre o princípio do gosto pela leitura: a iniciação literária através da literatura infantil.

Os textos, quando bem direcionados à criança, têm a capacidade de dialogar com seu próprio interior e de gerar experiências singulares. Nesse sentido, a percepção dos diferentes "outros" que se inter-relacionam durante 0 ato da leitura pode ser fortificada desde cedo. Para isso, basta percebermos a criança enquanto um sujeito carregado de sentidos.

Ao escrever um texto, o autor possui determinadas intenções e direciona sua escrita a um leitor esperado, ou seja, ele supõe a maneira como sua obra será recebida. Será que o autor de livros infantis pensa da mesma maneira? Sim. Nas obras infantis, compreendemos as maneiras diferenciadas de se perceber a criança e a infância a partir das concepções dos próprios autores, bem como da influência social que receberam. Ora, Seriója se emancipou após a contação da história feita pelo pai, pois já não foi mais o mesmo a partir do momento em que o texto repercutiu em seu interior.

A compreensão didática que se tinha da literatura infantil se perdeu na medida em que os textos foram apresentando a criança como um ser ativo e criativo. Hoje, inúmeros textos destinados ao público infantil aumentam o entrecruzamento de vozes, isto é, a percepção de que tanto o leitor quanto o autor carregam consigo uma narrativa interior, e dão espaço para que o receptor se posicione como um sujeito ativo.

A literatura infantil possui um papel fundamental no desenvolvimento das múltiplas infâncias. Desde cedo a criança tem a oportunidade de encontrar a realidade em que vive apresentada de outra forma, em um outro suporte (seja no livro, seja no dizer de um adulto). O livro infantil, assim como toda a literatura, contextualiza a sociedade e apresenta fatos que são inerentes à evolução da humanidade. Será que esse seria o motivo de os clássicos permanecerem entre nós 
e, muitos deles, se manterem atuais com o passar de gerações? O fato é que os livros retratam a vida em evolução e, ao mesmo tempo, nos fazem concluir coisas sobre a essência da vida humana.

É na infância que o ser humano tem a oportunidade de se constituir, de identificar e de (re)construir suas primeiras concepções sobre o mundo. Embora interagindo em culturas diferenciadas, desde o contexto familiar até o escolar, não há criança que, quando bem instigada, não se sinta atraída pelo texto literário. É ele que dará espaço para que sua imaginação aflore e para que sua capacidade criadora se destaque. Além disso, a literatura mantém uma forte rede de ligações intertextuais ao estabelecer um diálogo entre a obra, o autor, o contexto histórico em que se insere e o leitor. Ela possibilita um espaço de recriação, pois nenhum texto repercute de maneira igual nas pessoas que o recebem. Somos seres com experiências diferenciadas e, por isso, não sentimos da mesma maneira. A sensibilidade é característica singular e nós somos aquilo que nos contaram e aquilo que, consequentemente, contamos. Com certeza, no conto de Tchekhov, a narrativa interior de Seriója dialogou com o texto apresentado pelo pai!

\subsection{Os efeitos da leitura literária são diferentes em adultos e crianças?}

Como veremos mais adiante, a literatura tanto pode ser imposta como um instrumento didático quanto pode ser exercício de liberdade, emancipando a criatividade e o senso crítico do receptor. Para a criança, isso não é diferente. Quando uma narrativa Ihe é apresentada, ela identifica traços da realidade em que vive, no mundo da fantasia para o qual foi transportada. Viaja, então, por um caminho de descobertas e leva consigo um documento textual imprescindível: a sua própria história. Seriója, no conto de Tcheckov, demonstra a sua identidade enquanto criança e, ao mesmo tempo, a sua autonomia em construir o seu conhecimento a partir dos implícitos de uma narrativa. Seu pai, ao contar uma história, precisou adentrar outro mundo e, por mais que tivesse a convicção de que aquilo era mera ficção, naquele instante de tempo, sua emoção se deixou levar pela imaginação.

Levando em consideração o fato de que, quando lemos um texto literário vivenciamos outro tempo (o do "era uma vez"), não podemos esquecer que, em determinado momento, o nosso próprio texto irá conversar com o texto alheio, seja 
ele lido por nós mesmos ou proferido por outrem. Esse diálogo, na verdade, é inevitável. Afinal, se somos convidados a percorrer um caminho desconhecido, precisaremos confiar em nosso próprio eu, apesar de ele, assim como a história, estar frequentemente sendo (re)construído ou (re)descoberto.

O que fomos quando crianças e o que nos constitui enquanto seres adultos são polos extremamente vinculados ao que nos constitui seres humanos. Frequentemente, podemos recordar de tudo aquilo que repercutiu em nosso interior quando crianças. Bachelard (1989) nos lembra que o termo referido - repercussão baseia-se no fato de envolvimento integral do leitor pelo texto. Assim, concluímos que o ser adulto é a soma de todos os "outros" que já foi, pois há um entrecruzamento de experiências que o constitui. Afinal, estar "em crescimento" significa estar ludicamente inserido no mundo; estar em processo de viver é estar vivendo. A vida, na verdade, é uma conversa entre os textos do passado e os do presente. Dessa união, surgirão as produções futuras significando que, apesar do caminho que se escolha, todos alcançarão uma chegada de significações.

$\mathrm{Na}$ verdade, os textos referentes à literatura infantil são capazes de encantar tanto crianças quanto adultos: são divertidos, estimulam a imaginação, possuem linguagens e temáticas interessantes, são instigantes visualmente, etc. As obras infantis são aquelas totalmente adaptadas a esse universo. Se não apresentarem características básicas desse mundo, não são literatura infantil. Talvez, meras reprodutoras de uma educação formal disfarçadas com uma roupagem infantil.

$E$, por falar nisso, registramos o fato de a literatura infantil não predestinar seu público. Ela se dirige para aqueles que por ela se interessam. As histórias e poesias se incorporarão ao sujeito que se familiarizará com seus dizeres. Enfim, um texto só é capaz de causar repercussões se o leitor com ele se identificar, independentemente da faixa etária ou das múltiplas experiências vivenciadas.

Por isso, acreditamos que a literatura infantil seja um dos recursos que possa ser utilizado para a formação de cidadãos criativos, críticos e capazes de interagir positivamente na sociedade em que estão inseridos. As histórias e o dizer poético são alguns dos recursos que possibilitam o diálogo entre os diferentes mundos em que a criança interage, pois abarcam e dão suporte aos "princípios geradores das culturas de infância: interatividade, ludicidade, fantasia do real e reiteração" (BARBOSA, 2007, p. 1067). A linguagem literária é uma das que mais revela o 
conteúdo humano. Através dela podemos desvendar nossas emoções e lidar com nossas sensibilidades.

A literatura infantil engloba questões sobre as quais todos nós podemos tecer comentários. Isso porque, quando criança, o ser humano sente o mundo literário de uma forma e, quando adulto, o percebe de outra, inclusive tendo a oportunidade de transmiti-lo a outros sujeitos através de sua maneira singular de dizer. O que une as duas fases da vida é a magia de poder sentir, cada um ao seu modo, possuir a capacidade de se emocionar com o dizer de outrem de acordo com a bagagem de experiências sociais vivenciadas, dentre as quais a leitura se enquadra.

\subsection{Como a literatura pode ser oferecida ao leitor?}

Analisando a historicidade do surgimento da literatura infantil, percebemos que, durante muito tempo, foi considerada como um subgênero e desqualificada enquanto obra de arte (CADEMARTORI, 1994), o que ainda hoje é percebido em alguns espaços escolares. Em sua natureza social, emerge paralelamente ao fenômeno de idealização da criança e da infância. Isso porque é influenciada pelas transformações sociais vivenciadas pela sociedade burguesa europeia durante 0 século XVIII. Um fator de grande relevância é o surgimento da indústria, o que fez com que novas atenções fossem dadas à criança e às instituições em que convivia. Ocorrem modificações na estrutura familiar e a criança passa a desempenhar outro papel neste novo conceito de família.

Nesse contexto, a literatura infantil alia-se à pedagogia nascente, no sentido de pregar ensinamentos e preceitos morais. A escola passa a ser uma instituição de fundamental importância e, através dos livros (a produção editorial aumenta gradativamente) e da leitura, são impostas ideologias sociais. Em relação à criança, o livro é tido como um instrumento de transmissão de modelos adultos.

Porém, se primeiramente a literatura infantil servia apenas como um objeto pedagógico e era desvalorizada enquanto arte, atualmente, a sua permanência se garante pelo fato de cativar o leitor a que se destina. Com essa transformação através dos tempos, o universo infantil é traduzido de forma ficcional e a criança, ao entrar em contato com obras, tem a possibilidade de se identificar com os enredos. Isso ocorre porque, enquanto leitor ou ouvinte, a criança é um sujeito ativo que tem a capacidade de sentir seu mundo através do texto apresentado e refletir sobre ele. 
De acordo com Zilberman (1983), toda obra traz consigo uma concepção de infância, pois a criança é imaginada de acordo com a intenção que o autor carrega. Nessa perspectiva, podemos citar o conceito de assimetria extremamente comum nas obras infantis, que se refere ao fato de as histórias para crianças serem produzidas por adultos. $\mathrm{O}$ adulto possui uma ideia assimétrica de criança, ou seja, o texto é produzido de um lugar desigual. Não havendo essa correspondência entre o universo do autor e o de seu leitor/destinatário, o autor expressa suas considerações em relação à criança no mundo (CADEMARTORI, 1994). A obra que encantará o leitor-criança será aquela que mais se aproximar de seu universo, aquela em que o autor conseguir se transportar à infância, tendo em vista que a criança é um ser pensante e criativo. Se houver a dosagem do nível de assimetria, a criança não se sentirá "traída" se, por exemplo, for apresentada a um mundo no qual jamais poderia estar inserida.

Podemos falar ainda em textos emancipatórios, ou seja, aqueles que colocam a criança em um lugar diferenciado daquele em que estava antes do contato com a obra, como aconteceu com Seriója. São textos que permitem a formulação de conceitos próprios, dando liberdade às suas reflexões singulares. Por isso, quanto menos pedagógico, mais emancipatório será o texto; quanto mais pedagógico, mais assimétrico e com menos valor estético.

Em muitos casos, a escola utiliza a literatura unicamente com o objetivo de transmitir determinado conhecimento da grade curricular. Esquece que a experiência de leitura não pode ser padronizada. Se determinado aluno possui uma bagagem de experiências diferenciadas, nem sempre conseguirá sentir o mesmo que outro colega vivenciou com alguma leitura. Além do mais, o ato de ler não é uma ação de resultado imediato, mas uma experiência que vai sendo construída aos poucos. Quando a escola utiliza a literatura com o objetivo de transmitir "conteúdos estanques", deixa implícito o conceito de que a educação, para ela, não é singular, ou seja, assume o fato de que não considera o "eu" de cada estudante e acaba por lançar conteúdos estanques, que não abarcam a complexidade do que é viver e estar inserido no mundo.

O tom da moralidade com que, em muitos casos, a literatura é apresentada destrói as margens de criatividade que o leitor possui em relação ao texto. $\mathrm{Na}$ realidade, tais margens são extremamente curtas, o que caracteriza a obra pelo alto nível de assimetria e a baixa possibilidade de a criança atingir a emancipação. Esse 
fator retrata a convicção que o autor deixa implícita sobre a criança: um ser incapaz de apresentar inventividade e que precisa receber orientações dos adultos para que sua moral se desenvolva adequadamente. Essa concepção totalmente equivocada não abarca a compreensão de que o processo de significação do texto é algo gradativo e que acompanha o desenvolvimento do humano. Citando um exemplo através de um gênero textual, podemos dizer que

[...] todos os bons contos de fadas têm significados em muitos níveis; só a criança pode saber quais significados são importantes para ela no momento. À medida que cresce, a criança descobre novos aspectos destes contos bem conhecidos, e isto lhe dá a convicção de que realmente amadureceu em compreensão, já que a mesma estória agora revela tantas coisas novas para ela. (BETTELHEIM, 1996, p. 205).

Vigotsky (2004) também apresenta a ideia de que a escola ainda emprega a falsa literatura infantil, da qual as crianças são obrigadas a tirar exemplos morais, lições e sermões edificantes. O autor atenta para o fato de que é impossível estarmos certos do tipo de efeito moral que esse ou aquele livro irá exercer. A criança tem o direito de, a partir da leitura de uma história, formular concepções opostas às de seu professor, o qual tem o dever de saber que as consequências do uso do texto literário apenas com a finalidade moralizante serão vivenciadas em toda a sua educação, dentro e fora da escola.

O resultado é um amortecimento sistemático do sentimento estético, sua
substituição por um momento moral estranho à estética e daí a natural
repugnância estética que noventa e nove por cento dos alunos que
passaram pela escola secundária experimentam pela literatura clássica.
Muitos dos que se pronunciaram a favor da exclusão da literatura como
objeto de ensino escolar assumem precisamente esse ponto de vista e
afirmam que o melhor meio de difundir ódio a algum escritor e levar a que
ele não seja lido é introduzi-lo no currículo escolar. (VIGOTSKY, 2004,
p.328).

Soares (1999) atenta para o fato de que o termo escolarização é, realmente, específico da escola. Para a autora, não há como haver escola sem haver escolarização, pois é nesse ambiente em que se transmitem ou se constroem saberes como ações formais. Em suma, a escolarização é o processo que a constitui enquanto instituição. Entretanto, devemos ter em mente o fato de que a escolarização pode trazer benefícios ao discente na medida em que é percebido como um ser criativo e reflexivo. Nesse caso, o aluno tem a oportunidade de relacionar os conhecimentos formais adquiridos dentro da instituição com o contexto 
social em que vive. A leitura, por exemplo, pode ser uma prática contemplada nas mais variadas situações de letramento, as quais ocorrem dentro e fora da escola. Em síntese,

[...] adequada seria aquela escolarização que conduzisse eficazmente às práticas de leitura literária que ocorrem no contexto social e às atitudes e valores próprios do ideal de leitor que se quer formar; inadequada é aquela escolarização que deturpa, falsifica, distorce a literatura, afastando, e não aproximando, o aluno das práticas de leitura literária, desenvolvendo nele resistência ou aversão ao livro e ao ler. (SOARES, 1999, p. 47).

Nesse sentido, o termo "ensinar a ler" é usado de maneira equivocada. Não se trata de um ato de ensino, embora a escola tenha a concepção de que tudo precisa ser ensinado. Os adultos, sobretudo aqueles que têm contato com crianças, possuem a função de criar uma sensibilização, uma aproximação com o texto literário. Assim, para que isso ocorra, precisam ser sensíveis e sentir prazer em ter contato com ele, já que é somente dessa maneira que conseguirão despertar o gosto no outro. O texto, por conseguinte, deve ser sentido, experimentado.

É preciso considerar que a literatura faz parte de um todo artístico e que, por isso, não se pode utilizá-la na tentativa de provocar efeitos morais específicos ou para estudar a realidade. Além disso, a implantação da leitura literária na escola apenas como fonte de prazer também corre o risco de perder espaço para outros elementos: computadores, brinquedos, passeios, etc. Conforme Vigotsky (2004, p.331), "uma peculiaridade da fase infantil consiste em que a força imediata da vivência concreta e real é para a criança bem mais significativa do que a força de uma emoção imaginária".

$\mathrm{Na}$ verdade, não existem maneiras convictas para se "trabalhar o ensino do texto literário". O que há são discussões a respeito de como podemos enfocá-lo. Se o ato de ler não pode ser ensinado, o professor não poderá contar com um material de apoio pedagógico. Deverá criar sua forma de estimular o contato com ele, a partir das repercussões geradas em seu próprio interior (BACHELARD, 1989).

Aquele que sente o texto é capaz de auxiliar o outro a perceber o jogo que se instaura entre cada palavra poética. Dessa maneira, é aberto espaço para o lado humano. Passamos a respeitar os inúmeros significados dados a determinada produção, uma vez que possuímos a consciência de que existem muitas formas de perceber um só texto. Cada sujeito aproveita a produção, escrita ou oralizada, de 
determinada maneira, dando um ritmo (composto de som e silêncio) ao seu compreender e ao seu dizer.

\section{ENFIM, QUE CONHECIMENTO A LITERATURA PROPICIA?}

Sabemos que a literatura suscita conhecimento. Como vimos, o processo de aprendizado através da leitura literária perpassa todas as fases da vida. Ele realmente existe! No entanto, a definição para que conhecimento é de que esse se torna algo complexo ao caracterizarmos a literatura como a ciência das incertezas. Como incertezas podem gerar conhecimentos? É aí que se esconde o mistério, a dificuldade para a definição. Através das ponderações realizadas sobre o texto infantil, podemos tentar uma breve caracterização.

O conhecimento propiciado pela literatura é subjetivo. Não há como defini-lo com plena clareza, ele se manifesta de modo muito individual. Isso ocorre devido ao diálogo que se explana entre texto, autor e leitor. Se cada um carrega consigo um texto, ao lermos, a nossa produção de sentidos irá diferir da produção dos demais leitores.

Para respondermos a essa pergunta precisamos, também, perceber a atividade estética em seu sentido biológico. Afinal, a arte existe como uma necessidade vital. Assim, podemos dizer que a literatura provoca conhecimento porque surge de um processo de criação. As pessoas, quando escrevem, têm suas intenções. As pessoas, quando leem, têm objetivos. Na verdade, "a criação é a necessidade mais profunda do nosso psiquismo em termos de sublimação de algumas espécies inferiores de energia (VIGOTSKY, 2004, p.337). Aquilo que não podemos fazer, podemos viver através da leitura, isto é, o que fica sem realização em nossa vidas é sublimado durante 0 ato de ler.

Outro aspecto relevante a ser ressaltado na tentativa de resposta à pergunta é a importância da percepção em relação à obra de arte. Somos capazes de, através da observação e da reflexão, perceber na arte aquilo que nos toca, que nos sensibiliza. Portanto, para ler um texto literário, o leitor também precisa ser um poeta.

O leitor deve ser congenial ao poeta e, ao percebermos uma obra de arte, nós sempre a recriamos de forma nova. É legítimo definir os processos de percepção como processos de repetição e recriação do ato criador. Sendo 
assim, impõem-se inevitavelmente a conclusão de que eles são o mesmo tipo biológico de sublimação de algumas espécies de energia psíquica como o são os processos de criação. (VIGOTSKY, 2004, p. 337-338).

Vigotsky (2004) afirma, também, que a atividade estética provoca a catarse, os espíritos são liberados diante de paixões que o atormentam. Podemos dizer, assim, que arte possui certo efeito moral, "que se manifesta em certa elucidação interior do mundo psíquico, em certa superação dos conflitos íntimos e, consequentemente, na liberação de certas forças constrangidas e reprimidas, particularmente das forças do comportamento moral" (VIGOTSKY, 2004, p.340). A vivência estética é uma forma de superação de conflitos e de vivências. Seu efeito cognitivo deixa vestígios em nosso comportamento. Ao lermos, ocorre um processo de transformação. Será que podemos dizer que esse é o conhecimento provocado pela literatura: o conhecimento de si, o conhecimento do mundo?

A palavra poética é algo sempre presente em nossas vidas, uma vez que o simples contato com a linguagem já nos induz a isso. Se pararmos para pensar, o nível de complexidade desse contato com a língua aumenta gradativamente, de acordo com as possibilidades do sujeito. Primeiramente, somos expostos aos acalantos, aos brincos, ou seja, a um fazer com palavras que encanta pelo som, pelo ritmo, pela brincadeira em si. $\mathrm{Na}$ medida em que vamos nos constituindo sujeitos de nossas próprias ações, passamos a conhecer as parlendas, os travalínguas, as cantigas de roda, as narrativas, enfim, os jogos linguísticos que promovem alegria, tensão e divertimento, conforme Huizinga (1999).

Ao lermos ou escutarmos uma história, nos dispomos a interagir dialogicamente, pois não somos agentes passivos. Somos indivíduos pensantes e, por isso, cada história nos traz uma carga de significantes e significados. Há fortes relações intrínsecas ao autor, ao texto e ao receptor (leitor, quando lemos; ouvintes, quando uma narrativa nos é contada ou quando um poema nos é dito). Essas relações precisam estabelecer sentidos.

De acordo com Eco (2005, p. 28) "[...] interpretar um texto significa explicar porque essas palavras podem fazer várias coisas (e não outras) através do modo pelo qual são interpretadas". Na verdade, para o autor, não há como definirmos a interpretação, pois o significado de uma mesma obra poderá oscilar, se deslocar de acordo com cada leitura realizada. Apesar de existirem critérios que limitam a 
interpretação (nem todo o dizer sobre determinado texto é aceito), o leitor precisa compreender que "o segredo de um texto é o seu vazio" (ECO, 2005, p. 46)

Nessa perspectiva, podemos lembrar Machado (2004), quando, ao falar da preparação de um contador de histórias expõe a pergunta: "[...] história, o que você tem para mim e o que eu tenho para você?". Através desse questionamento, são delimitados os contextos de significações. O contador passa a conhecer toda a sequência narrativa, escolhendo estratégias para elaboração de um roteiro a partir das articulações com sua própria experiência pessoal. Aos poucos, a história vai se colorindo, ganhando ritmo e pulsação. Esse mesmo processo acontece com o leitor. E seria essa a resposta para aquilo que estamos procurando?

Ainda não temos plena convicção e acreditamos que nunca a teremos. Mas, por tudo aquilo que refletimos, temos condições de afirmar que muitas de ações cotidianas são motivadas por nossas leituras, pois elas propiciam uma nova forma de conhecer e de perceber a realidade. A literatura nos apresenta verdades e, por isso, nos ensina. De acordo com Gai (2009, p. 138), a

[...] "verdade" da narrativa ficcional e o conhecimento a ela inerente podem mobilizar os indivíduos leitores em sua própria vida, em suas convicções e em seu conhecimento de $\mathrm{si}$, em sua subjetividade, o que significa que possui um alto potencial educativo.

Nesse mesmo sentido, Gai (2009) continua argumentando que, quando lemos, ativamos nossa imaginação e conhecemos experiências que foram construídas por outros, ou seja, as palavras que nos são apresentadas em uma obra ficcional criam outros mundos e nos mostram possibilidades de ação. Por isso, podemos afirmar que esse conhecimento veiculado pela literatura é de difícil sistematização, pois se manifesta de maneira muito singular.

Acreditamos que essas possibilidades de respostas sintetizam uma qualidade preponderante da obra artística: o poder de sedução. A literatura encanta seus receptores, seja através do texto dito ou do texto lido. A sedução propiciada pelo contato com os vários mundos fictícios explica a característica da reflexão humana. Somos seduzidos porque pensamos, porque nos projetamos em outro universo, que é o espaço das possibilidades, da criatividade. O texto que deu início a este artigo, o conto "Em casa", fala de sedução, de encantamento. Aquele menino de sete anos foi 
seduzido pelas palavras que foram apresentadas pelo pai na forma artística de uma narrativa. E quantas vezes já fomos um Seriója? Inúmeras, com certeza.

\section{RESPONDENDO E FINALIZANDO...}

Finalmente, a resposta explicitada no título será respondida: o que esse texto quer [ou não quer] dizer? Vamos lá! Este artigo tem uma determinada intenção: a de apresentar reflexões sobre o conhecimento oportunizado pela literatura, levando em consideração, sobretudo, a literatura infantil. No entanto, o documento "não quer dizer nada", pois sua significância depende do leitor.

O que objetivamos foi a construção de um texto baseado em perguntas e acrescidas de possíveis respostas, pois se a literatura pode ser considerada como a ciência das incertezas não há como termos muitas convicções. Por isso, a resposta que menos será clara é justamente a que intitula o texto. Se nossa intenção foi a de propiciar reflexões, precisamos de leitores para respondê-la. Brincamos, dessa maneira, com tal questionamento, extremamente realizado após leituras (atividades que, em algumas instituições, tem objetivos meramente avaliativos), mas que, na verdade, não possui muito fundamento. Não há como respondermos "o que um texto quer dizer". A resposta irá sofrer variações todas as vezes que a leitura for feita por leitores diferentes ou até mesmo quando o mesmo leitor ler o mesmo texto outra vez. As possíveis respostas, na realidade, estarão respondendo a um outro questionamento: como é o conhecimento propiciado pela literatura. Para este, já temos uma resposta: um conhecimento que é subjetivo, o conhecimento de si, mas ao mesmo tempo o conhecimento do mundo. Este texto, então, dá margens para a construção da reflexão sobre algo que é fundamental na vida: o desejo de ler, o desejo de conhecer e a conclusão de que o que sabemos não passa de incertezas.

\section{NOTAS}

\footnotetext{
${ }^{1}$ Aluna do Mestrado em Letras - Leitura e Cognição/UNISC; bolsista PROSUP/CAPES..

2 Docente do PPG em Letras - Mestrado e do Departamento de Letras, da Universidade de Santa Cruz do Sul - UNISC, pesquisador com recurso do Edital PqG 2012 - Fapergs.
} 


\section{REFERÊNCIAS}

BACHELARD, Gaston. A poética do espaço. Trad. Antônio de Pádua Danesi. São Paulo: Martins Fontes, 1989.

BARBOSA, M. C. S. Culturas escolares, culturas de infância e culturas familiares: as socializações e a escolarização no entretecer destas culturas. Educação e Sociedade, Campinas, n. 100 - especial. v. 28, p. 1059-1083, out. 2007. Disponível em: <http://www.cedes.unicamp.br>. Acesso em: 25 nov. 2011.

BETTELHEIM, Bruno. A psicanálise dos contos de fadas. Trad. Arlene Caetano. 11. ed. Rio de Janeiro: Paz e Terra, 1996.

CADEMARTORI, Ligia. O que é literatura infantil. 7. ed. São Paulo: Brasiliense, 1994. Coleção Primeiros Passos, 163.

ECO, Umberto. Interpretação e história. In: Interpretação e superinterpretação. 2. ed. São Paulo: Martins Fontes, 2005. p. 27-51.

GAI, Eunice Terezinha Piazza. Narrativas e conhecimento. Revista Desenredo, Passo Fundo, n. 2, v. 5, p. 137-144, jul./dez.2009. Disponível em: <http://www.upf.edu.br/seer/index.php/rd/article/download/1247/760>. Acesso em: 15 mai. 2013.

HUIZINGA, Johan. Natureza e significado do jogo como fenômeno cultural. In: . Homo ludens: o jogo como elemento da cultura. 4. ed. São Paulo:

Perspectivas, 1999.

MACHADO, Regina. Acordais: fundamentos teórico-poéticos da arte de contar histórias. São Paulo: DCL, 2004.

SOARES, Magda. A escolarização da leitura infantil e juvenil. In: BRANDÃO, M. B.; EVANGELISTA, A. A. M.; MACHADO, M. Z. V. (Orgs.). A escolarização da leitura literária: o jogo do livro infantil e juvenil. Belo Horizonte: Autêntica, 1999.

TECHKHOV, Anton Pavlovitch. Um homem extraordinário e outras histórias. Trad. Tatiana Belinkv. Porto Alegre: L\&PM, 2009.

VIGOTSKY, Lev Semenovich. A educação estética. In: Psicologia pedagógica. Trad. Paulo Bezerra. 2. ed. São Paulo: Martins Fontes, 2004. p. 323363.

ZILBERMAN, Regina. O lugar do leitor na produção e recepção da literatura infantil. In: KHÉDE, Sônia Salomão (Org.). Literatura Infantojuvenil: um gênero polêmico. Rio de Janeiro: Vozes, 1983. 